\title{
Correction to: On some multiplicative version topological indices of block shift and hierarchical hypercube networks
}

\author{
Prosanta Sarkar $^{1}$ (D) $\cdot$ Nilanjan $\mathrm{De}^{2} \cdot$ Anita Pal $^{1}$
}

Published online: 7 July 2021

(c) Operational Research Society of India 2021

\section{Correction to: OPSEARCH https://doi.org/10.1007/s12597-021-00539-z}

The affiliation of the author Anita Pal was wrongly missed in the online publication.

It is corrected as:

Department of Mathematics, National Institute of Technology Durgapur, India. Kindly consider.

Publisher's Note Springer Nature remains neutral with regard to jurisdictional claims in published maps and institutional affiliations.

The original article can be found online at https://doi.org/10.1007/s12597-021-00539-z.

Prosanta Sarkar

prosantasarkar87@gmail.com

Nilanjan De

de.nilanjan@rediffmail.com

Anita Pal

anita.buie@gmail.com

1 Department of Mathematics, National Institute of Technology Durgapur, Durgapur, India

2 Department of Basic Sciences and Humanities (Mathematics), Calcutta Institute of Engineering and Management, Kolkata, India 